\title{
Fatty Liver Disease among other Comorbidities Requiring Early Diagnosis in Pediatric Obesity
}

\author{
Manuel Moya*, Mercedes J uste \\ Pediatric Department, University Miguel Hernández, S Juan University Hospital, Alicante, Spain
}

\begin{abstract}
Received: November 29, 2013; Accepted: December 16, 2013; Published: December 19, 2013
*Corresponding author: Manuel Moya, Pediatric Department. University Miguel Hernández, S Juan University Hospital, Alicante, Spain; Tel: 00-34 -965- 919-430; E-mail: Manuel.Moya@umh.es
\end{abstract}

\begin{abstract}
Introduction: In adults obesity is normally accompanied by complications known as comorbidities. The most important are type 2 diabetes, cardiovascular disease and non-alcoholic fatty liver disease because of their clinical burden and the associated risk of premature death. Although they do exist in pediatric ages, they are not fully considered in obese children and adolescents.

Objective: To make pediatricians aware of the real prevalence of comorbidities and metabolic syndrome as common stage prior to them and the necessity of an earlier diagnosis.

Comorbidities recent outcomes: Four main search engines were used for obtaining the present information on prevalence, etiology and pathogenesis of pediatric comorbidities. There is a growing prevalence of non alcoholic fatty liver disease (NAFLD) and type 2 diabetes (T2D): The analysis of the different causes shows that besides obesity and unbalanced energy intake, genetic predisposition is the most important. Pathogenesis is related to the concept and evolving status of insulin resistance (IR) being basic for detection in compensation phase.
\end{abstract}

Non-alcoholic fatty liver disease: An analysis of different metabolic syndrome (MetS) definitions has been made and after applying the IDF definition its clinical usefulness was evident. Non-alcoholic fatty liver disease is treated more extensively because it is the most common liver abnormality in pediatric ages, also because of the eventual evolution to steatohepatitis (and cirrhosis) and particularly for the difficulties of an early diagnosis. Consequently the noninvasive methods should be tried before the gold standard liver biopsy.

Prevention and care are also considered including pharmacologica therapy.

Conclusion: Comorbidities in the obese child and adolescent are frequently overlooked although they are the real origin of the severe complications in adult life.

Keywords: Obesity; Obesity comorbidities; Metabolic syndrome Insulin resistance; Fatty liver; Human

\section{Abbreviations}

BMI: Body Mass Index; CVD: Cardiovascular diseases; DAG: Diacylglycerol; FFA: Free fatty acidsl; GNG: Gluconeogenesis; IR: Insulin resistance; NAFLD: Nonalcoholic fatty liver disease; MetS: Metabolic syndrome; T2D: Type 2 diabetes; TAG: Triacylglycerol; TG: Triglycerides

\section{Introduction}

In a general population obesity is normally accompanied by a series of complications that are known as comorbidities or comorbid states that include type 2 diabetes (T2D), cardiovascular diseases (CVD) [1], non alcoholic fatty liver disease (NAFLD) [2], hyperuricemia [3], hemostatic diseases [4], and respiratory disorders. The first three are the most important as they can result in premature death. Although they are also a reality in the case of pediatric obesity, they are often not adequately evaluated because of their clinical subtleness and a general idea that they are adult clinical problems despite their origin in pediatric ages. It can be said that at least in T2D, CVD and NAFLD, insulin resistance (plus leptin resistance and proinflammatory adipokines) is a common and determinant factor as will be shown below. The metabolic syndrome (Met S) as it is accepted at present is made up of obesity, impaired glucose homeostasis, hypertension and dislipemia and has the advantage of being highly predictive of T2D and CVD especially if it appears in obese children or adolescents [5]. This precursory character has been accepted as one of its strong points but is less so for NAFLD which sometimes is the first of the comorbidities.

Metabolic syndrome was first described in 1920 in Sweden but the concept spread in English literature from the 1950s [6]. In the 1980s, Reaven [7] linked Met S to insulin resistance (Syndrome X), but only recently has a consensus been reached through the initiative of the International Diabetes Federation [8, 9]. Unfortunately a single definition for Met $S$ for children and adolescents does not exist. In the course of this review, we have found 11 different definitions Table 1 with varying cut-off points. One of these even uses adult parameters for pediatric cases. Again a consensus of the International Diabetes Federation [10] proposed a definition for different pediatric ages, ie 6-10 yrs; 10-16 yrs and over 16 yrs. Table 2. It is important to establish a single definition because according to which definition is applied the frequency can double [11]. This definition of growing consensus differs from the adult one because of the obligatory presence of visceral adiposity due to the proven action as an 
Table 1: PREVALENCE OF METABOLIC SYNDROME Met S) IN PEDIATRICS.

\begin{tabular}{|l|l|}
\hline Number of studies & 15 \\
\hline Number of patients & 25433 \\
\hline Number of patients /study & $128-13383$ \\
\hline Number of studies using IDF & 8 \\
\hline Met S in total population & $2.3 \%-11.5 \%$ \\
\hline Met S in overweight & $6.7 \%-30.8 \%$ \\
\hline
\end{tabular}

Study of cohorts (level 4 of evidence) in 13 countries according to the different used definitions (References 8 -11, 18, 20 - 22, 24)

independent factor for insulin resistance. It can be evaluated through abdominal circumference as well as those on abdominal (trunk) fat obtained through DXA or MRI. This definition of Met S is a unified method of diagnosis in clinical care that can be used everywhere and allows comparison of children and adolescents (and adults) from different areas or countries.

The aim of this review is to update the prevalence, pathophysiology and clinical aspects of present comorbidities in pediatric obesity and to make pediatricians aware of the importance of an early diagnosis.

\section{Comorbidities recent outcomes}

To analyze prevalence and pathophysiology a literature search has been made through PubMed, Cochrane Database of Systematic Reviews, Medscape (for treatment) and Scopus. After the search the obtained references were: Scopus: 286, PubMed 142, Medscape 78 and Cochrane Database 17. In the first two searches the temporal limit was of 10 years and was limited to humans. Only the base of PubMed allowed a controlled search and the used descriptors: Fatty Liver, Metabolic Syndrome X, Comorbidity, Obesity, Abdominal obesity. After the primary selection, results obtained from PubMed data base were mainly chosen due to the fact of the combination of free and controlled search being possible

\section{Prevalence}

It is difficult to approach frequency due to the lack of uniformity of diagnosis for T2D, CVD or NAFLD in pediatric ages. In a valuable non-systematic review Lobstein [12], made an estimation for the pediatric European population of 20,000 cases of T2D, 400,000 cases of altered glucose tolerance test and more than 1,000,000 with CVD stigmata. More recently the NHANES 1999-2008 survey [13] on more than 3000 participants aged 12 to 19 years showed a prevalence of $14 \%$ for prehypertension/ hypertension, $22 \%$ for borderline-high/ high LDL cholesterol, $6 \%$ for low HDL cholesterol and $15 \%$ for prediabetes/ diabetes. The figures for cardiovascular risk were greater if the adolescents were overweight or obese. The important problem is that according to hypertension screening during ambulatory pediatric visits, basic facts are disregarded [14]. In two- thirds of cases, blood pressure was not measured and/or the sodium intake related to systolic blood pressure increases was largely ignored [15]. Finally the important data from a systematic review and meta-analysis of nearly 50,000 children [16] show that being overweight or obese implies a systolic blood pressure of 4.54 $\mathrm{mm} \mathrm{Hg}$ and $7.49 \mathrm{~mm} \mathrm{Hg}$ respectively above the levels of the controls. Apart from the expected change in the lipidic profile and fasting insulin levels, this study shows that children have a significant increase in the left ventricular mass. According to our own experience [17] if, in addition, the interventricular septum thickness measurement were used as a screening method, the diagnosis of CVD in otherwise 'healthy' obese children would erode this widespread misconception. In Metabolic syndrome, it is worth analyzing the evolution of its frequency. In the data from NHANES III [18] which assessed nearly 2,500 adolescents, between 1988 and 94, through the National Cholesterol Education Program (Adult Treatment Panel III), the prevalence was $4.2 \%$ in the general population (28.7\% in the overweight). Similar data appeared in different US studies over the same period. In comparison with this so called scratch situation in the last 20 years and using the same definition [NCEP] prevalence has doubled [19]. In other emerging areas such as Korea [20] or Brazil [21], frequency is also growing.

\section{Causes of comorbidities}

The Raine study, carried out in Australia [22], shows that rises in glycemic load evaluated after a three-day survey independently increase the risk of Met S. Similar conclusions arise from a large study in US [23]. Rises in plasma uric acid in preadolescents [3] coincide with two or more cardiometabolic risk factors, as in the NHANES 1999-2006 [24], particularly if there is an increase in waist circumference. Hyperuricemia will

Table 2: The IDF definition of the Risk Group and Metabolic Syndrome in Children and Adolescents [REF 8].

\begin{tabular}{|c|c|c|c|c|c|}
\hline Age group (years) & Obesity (WC) & Triglycerides & HDL-C & Blood pressure & $\begin{array}{l}\text { Fasting plasma } \\
\text { glucose }\end{array}$ \\
\hline $\begin{array}{l}6-<10 \\
10-<16\end{array}$ & $\begin{array}{l}>90^{\circ} \text { percentile } \\
>90 \text { th percentile or adult } \\
\text { cut-off if lower }\end{array}$ & $150 \mathrm{mg} / \mathrm{dL}$ & $<40 \mathrm{mg} / \mathrm{dL}$ & $\begin{array}{l}\text { Systolic BP > } 130 \text { or } \\
\text { diastolic BP? } 85 \mathrm{~mm} \mathrm{Hg}\end{array}$ & $\begin{array}{r}\text { FPG } 100 \mathrm{mg} / \mathrm{dL} \text { or } \\
\text { known T2DM }\end{array}$ \\
\hline 16 + (Adult criteria) & $\begin{array}{c}\text { WC }>94 \mathrm{~cm} \text { for Europid } \\
\text { males and }>80 \mathrm{~cm} \text { for } \\
\text { Europid females, (with } \\
\text { ethnic-specific values for } \\
\text { other groups) }\end{array}$ & $\begin{array}{c}>150 \mathrm{mg} / \mathrm{dL} \text { or } \\
\text { specific treatment } \\
\text { for high } \\
\text { triglycerides }\end{array}$ & $\begin{array}{l}<40 \mathrm{mg} / \mathrm{dL} \text { in males } \\
\text { and }<50 \mathrm{mg} / \mathrm{dL} \text { in } \\
\text { females, or specific } \\
\text { treatment for low HDL }\end{array}$ & $\begin{array}{c}\text { Systolic BP >_1 } 130 \text { or } \\
\text { diastolic BP >_85 mm Hg } \\
\text { or treatment of previously } \\
\text { diagnosed hypertension }\end{array}$ & $\begin{array}{l}\text { FPG } 100 \mathrm{mg} / \mathrm{dL} \text { or } \\
\text { known T2DM }\end{array}$ \\
\hline
\end{tabular}

For clinical purposes, but not for diagnosing the MetS, if FPG 5.6-6.9 mmol/L (10 (M25 mg/dL) and not know to have diabetes, an Oral Glucose Tolerance Test should be performed. Diagnosing the metabolic syndrome requires the presence of central obesity plus any two of the other four factors. 
also provide information on protein intake besides its added diagnostic values. On this point, it is also worth considering other surrogate factors of Met $\mathrm{S}$ such as fasting insulin levels, HbA1c and high sensitivity CRP, the use of which raises the predictive capacity [25] particularly if waist circumference is measured [26]. This leads to the question whether they should be considered diagnostic or causative factors. The excessive intake of energy and fats is an important cause. Physical activity. If sedentary lifestyles are considered first, it is clear that screen time greater than 35 hours per week will increase the prevalence of Met $S$ and comorbidities [27], it has also been demonstrated in the NHANES 2003-4 [28], that the counterproof exists; vigorous physical activity is not associated with comorbities. Sleep duration of less than 8 hours per day in obese children is also associated with Met S [29]. These circumstances, together with mechanization, central heating and fewer playgrounds, all contribute to increases in obesity.

This causal approach could be concluded with the consideration of the Mexican studies in severe obese adolescents [30]: $13 \%$ do not show Met S and neither do obese patients suffering from Prader-Willi syndrome [31] Prevalence studies always show a proportion of non-overweight children and adolescents who are affected by comorbidities or MetS. In the US/ Korea study [2], this proportion is $0.7 \%$ of the population of 12 19 year-olds. This is a suitable framework to evaluate individual predisposition after gene analysis and genome-wide studies [32]. Preliminary results show a certain variety of pleiotropic genes (responsible for different phenotypic traits) that are involved but only cause moderate effect; in the case of Met S, only $10 \%$ of its variability is related to genetic grounds [33]. The PTEN (tumor suppressor phosphatase and tensing homologue) gene haploinsufficiency leading to low insulin resistance and obesity [34] in the Cowden syndrome, or the variation of adiponectin activity, or SRBP-1c (sterol regulatory element binding protein 1c) [35] could represent a model for explaining the different appearance of comorbidities.

\section{Pathophysiology}

Insulin resistance is defined as a state of blunted response(s) to present levels of circulating insulin. Because insulin has a multiplicity of actions wider than the mere conservation of euglycemia, they can explain certain pathogenetic aspects of comorbidities and Met S. Insulin resistance evolves through three phases: the first is the compensation phase where raised insulin levels maintain normal levels of glycemia. After a normally prolonged period this phase is followed by one in which hyperglycemia occurs after meals or even during fasting. In the third phase glycemia remains high throughout the 24 hours and T2D is established and insulin resistance status ends. In this phase there is insulin deficiency and an increase in alpha cells with enhanced glucagon production Figure 1. Oral glucose challenge could identify the insulin sensitive or resistant status but keeping in mind that this transit is also a different continuum in different tissues. Classic studies with hyper and euglycemic clamps in normal subjects [36] showed that hypeglycemia decreases beta cells sensitivity to blood glucose variation. There is ample evidence [37] on how the coexistence of insulin resistance (insulinemia $>2 \mathrm{SD}$ ) increases the risk of other metabolic disturbances of Met $\mathrm{S}$ components and consequent comorbidities.

\section{Mechanisms leading to insulin resistance}

The first step is the positive energetic balance in the obese child with the elevation of fatty acids and other lipids together with hyperglycemia that follows frequent food intake. Raised insulin levels are crucial for the increased fat content of the adipocyte due to the stimulation of lipoprotein lipase activity that favors the entrance of fatty acids. Insulin also directly favors the entry into adipocyte of glucose which is the natural precursor of intracytoplasmic glycerol and then the synthesis of triacylglycerols occurs, almost the unique component of the intracellular droplet. When this increment takes place in the abdominal cavity, it will have more important consequences than when it does so in subcutaneous adipose tissue Table 3 as will be seen below. In the insulin resistant status abdominal adipocytes lipolysis is increased with a release of FFA into the portal system and then to the liver with the important consequences of this accumulation as can be seen in the next stage. The richer vagal innervation of perivisceral fat implies an easier lipolysis and increase of free fatty acids in the blood stream [38]. Concerning abdominal obesity, the wider adult experience [39] indicates that even when assessed through waist circumference, it has a greater diagnostic capacity than BMI [40] and this has been recognized in pediatric ages $[41,42]$. The consequences of visceral fat accumulation are summarized in Figure 2. The cellular mechanisms are beyond the present aim but schematically, in the hepatocyte, the chronic and high insulinemia levels are not able to decrease the gluconeogenesis. Besides, these are stimulating the de novo lipogenesis. Both circumstances together with the postabsorptive supply give way to an export of VLDL contributing

\section{Insulin resistance development throughout childhood}
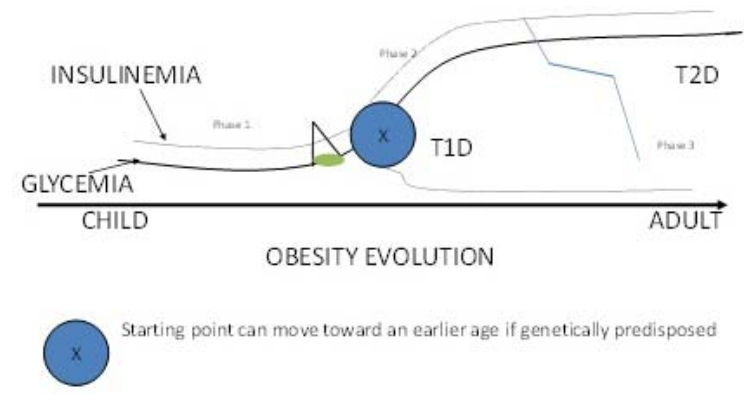

Figure 1: Phase 1 or compensation, insulin higher levels maintain glycemia. Phase 2 or insulin resistance itself, higher levels of insulin do not control postprandial or fasting hyperglycemia. Phase 3 or T2D, insulin levels decrease because of the dysfunction of beta-cells and decrease of beta-cells mass $[70,79]$. 
to the dislipemia and also to hyperglycemia due to the added decrease of activity of the GLUT 4 owing to the action of DAGs on the insulin receptor substrate (IRS).

\section{Non-alcoholic fatty liver disease (NAFLD)}

The non-alcoholic fatty liver disease will be treated more extensively because it is the most common liver abnormality in pediatric ages, because of the eventual evolution to steatohepatitis (and cirrhosis) and particularly for the difficulties of an early diagnosis. In this part the clinical results of our own patients are included.

Non-alcoholic fatty liver disease is a co-morbidity of obesity caused by accumulated macrovesicular fat, triglycerides, in the hepatocyte, worsened by hyperinsulinemia with a poorly and unpredictable progression to steatohepatitis [43]. It was first described in 1952 by Zelman in obese adults and in 1983 in pediatrics by Morant [44].

Fatty liver develops when fatty acid uptake and the novo

Table 3: Fat Distribution.

Visceral fat is located in the abdominal cavity among the:
Stomach
Liver
Gall bladder
Pancreas
Small intestine and mesentery
Large intestine
Perinephric fat and epididymal fat

Subcutaneous fat also includes

Hips

Thighs

Buttocks

\section{VISCERAL FAT PROVED CONSEQUENCES}

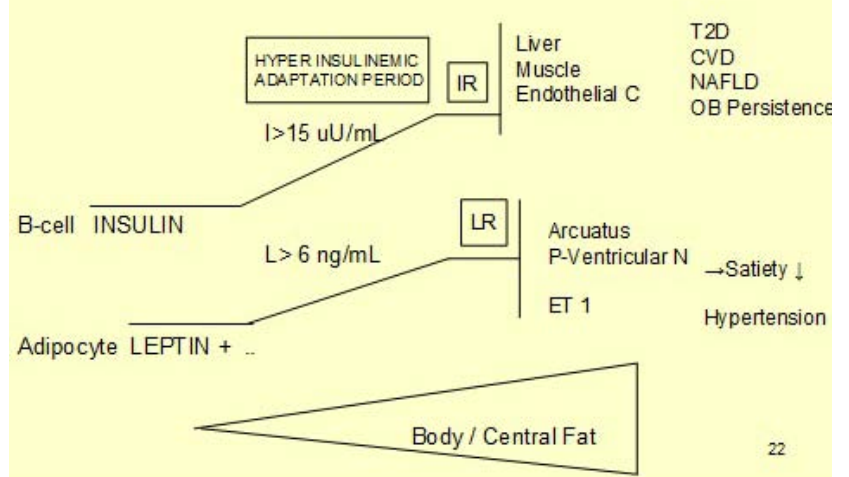

Figure 2: Clinical consequences are particularly important in the case of the increased abdominal fat. Insulin higher levels acting on the target tissues will lead to the comorbidities. Leptin higher levels will contribute to obesity maintenance. fatty acid synthesis exceed fatty acid oxidation and export as very low-density lipoproteins o triglycerides. The uptaken fatty acids have two origins: dietary and adipose tissue. Around $20 \%$ of dietary fats go directly to the liver, which is an important quota, but dietary carbohydrates also promote de novo synthesis of FFA from acetyl-coenzyme A and the insulin stimulated SREBP-1c as seen above and the stimulation of the transcription factor carbohydrate responsive element-binding protein (ChREBP) that also stimulates the FFA synthesis [45]. Fructose plays a special role because unlike circulating glucose it is taken solely by the liver [46] and because its phosphorylation occurs in carbon 1, it cannot be incorporated to the metabolic path of glycogen synthesis, instead it is converted into glycerladehyde -3 phosphate which is an adequate substrate for the novo lipogenesis. This fact is important in light of the growing consumption of sucrose. Normally in the visceral adipose tissue and during fasting, TG hydrolysis is carried out by the adipocyte TG hydrolase and a fraction of this is transported by albumin to the liver. This hepatic fatty acid deposit has three main destinations: oxidation in mitochondria, reesterification as TG and stored and finally added to apolipoproteins and excreted as VLDL. If the uptake is greater than the sum of oxidation and export quotas, the storing will increase. This does not occur in all individuals nor in all obese individuals with positive energy balance, therefore underlying circumstances or genetic causes [47] should be considered, namely monogenic defects (PNPLA3, Apo A5..,) gender and ethnicity and predisposition picked up by genome-wide association studies. The better known cellular mechanisms [48] reveal that in humans DAG content in the liver is the best predictor of insulin resistance, through protein kinase epsilon and its inherent consequences as described above.

Prevalence of NAFLD varies according to the evaluation method, if for example, high definition ultrasound plus AST /ALT elevation is used then prevalence ranges between $10-77 \%$ [49], which clearly implies a low specificity. Schwimmer [50] reviewed 742 autopsies from children and adolescents after accidental death, fatty liver [equal or greater than $5 \%$ of hepatocytes containing macrovesicular fat, droplet equal or larger than nucleus] was found in 97 cases and 38\% of them were overweight or obese. This gives a more realistic figure for prevalence. As the prevalence of pediatric obesity has risen so have comorbidities with priority of NAFLD. This has been considered a common liver disease in adults but also in pediatric ages now the development of detection methods is on the verge of generalization.

\section{Fat liver histology}

Steatosis is defined as a hepatic TG content greater than the 95th percentile [ $\sim 55 \mathrm{mg} / \mathrm{g}$ of liver] for lean healthy individuals [51] or as is more usual when more than $5 \%$ of hepatocytes contain fat droplets equal or greater than the nuclear size [76]. Hepatic steatosis is often self-limited but it can progress to non-alchoholic steatoheaptitis (NASH). There are two different forms of NAFLD [52]. Type I implies hepatocyte ballooning and cell injury/death, an inflammatory infiltrate and perisinusoidal fibrosis and is closer to the adult type, is less common in pediatrics and it predominantly affects girls. Type II is the habitual form in 
pediatric obesity; it is characterized by macrovesicular steatosis plus portal inflammation, periportal mononuclear cell infiltration and portal fibrosis. It is different from the adult type which in addition shows ballooning degeneration, perisinusoidal fibrosis and PMN infiltration. We have studied seven obese children and adolescents suffering from NAFLD, out of them there were five cases of type II steatosis, a case of steatohepatitis, and a case of Wilson disease. Figure 3 shows a portal space of one of our patients with typical pediatric pattern. Histology is probably at present the gold standard for evaluating fat liver, but liver biopsies are quite an invasive procedure, therefore strict criteria are imposed in our Unit, trunk fat $>40 \%$, raised AST, ALT and gamma GT and fasting insulinemia $>15 \mathrm{uU} / \mathrm{ml}$. The rationale for liver biopsy and a complete histopathologic description and evaluation can be found elsewhere [53].

\section{Clinical clues}

Despite its high prevalence, NAFLD is largely underdiagnosed, probably because it is a clinico-pathological diagnosis and most children are asymptomatic. Diagnosis depends on the eventual finding of hepatomegaly and elevated aminotransferases. If waist circumference is above the 90th percentile, then suspicion grows and may even imply liver fibrosis [54]. Serum liver enzymes alone have low sensitivity and specificity according to previous biopsy levels but they can be helpful when measuring AST, ALT and gamma-GT in an obese child older than 3 years with an increase in waist circumference and with history of NAFLD in relatives $[55,56]$.

Image techniques. Liver biopsy remains as the gold standard, it can qualify the degree of steatosis, stage liver fibrosis and assess the degree of liver cells injury, but percutaneous biopsy has a certain risk of bleeding and requires experience and a hospital setting. Clinico-pathological correlation is necessary in each individual case because the histology is similar regardless of etiology: drug toxicity (steroids, antiretrovirals), metabolic diseases (Wilson disease, tyrosinemia, and total parenteral nutrition), severe pediatric malnutrition or adult alcohol



Figure 3: A portal space of one of our patients with typical pediatric pattern appears: macrovesicular steatosis [no ballooning] and inflammatory pattern with MN cells. On the right of the picture [ Masson's trichrome stain] a portal fibrosis can be seen. HUSJ biopsies from 7 severe obese children: steatohepatitis 1; type II 5; other 1 . consumption [57]. MRI can be used previously, which allows a quite accurate diagnosis and measurement of the fat liver deposit. It is easy to perform and interpret and in adult patients has demonstrated a good correlation between hepatic steatosis and liver biopsies. In pediatric ages and using this technique the hepatic fat fractions in lean and obese children can be measured and when this proportion is over $8.7 \%$ it indicates a mild steatosis [58]. New techniques using intravenous contrast enable an assessment of the degree of fibrosis. MRS has the capacity to detect minimal amounts of fat in the hepatocyte but its availability in clinical practice is restricted. Ultrasound, although less precise is the most employed modality because of safety, availability and cost. Its weak points are that it only detects steatosis greater than $30 \%$, the attenuation of the US beam by fat outside the liver and its subjectivity. When an ultrasound score (0-3) based on hepatorenal echo contrast, liver echogenicity, visualization of intrahepatic vessels and visualization of liver parenchima and diaphragm is used, the result is a good correlation with histological classification [59]. Ultrasonic transient elastography, alone or together with pediatric NAFLD fibrosis index is used more for following hepatic fibrosis in a determined chronic patient [60]. It is important to consider that NAFLD precedes T2D and probably metabolic syndrome itself, thus the importance of its diagnosis.

\section{Prognosis}

Although simple steatosis is largely benign and nonprogressive, this fat liver is associated with cardiovascular disease and type 2 diabetes to a greater extent than obesity without this co-morbidity. Chronic NAFLD can progress to NASH. Once in the stage of NASH, the progressive severity of this condition towards fibrosis and cirrhosis increases [52]. Due to the chronic spectrum it is pertinent to consider that in the adult $[61,62]$ cirrhosis develops in a proportion of $10-30 \%$ after ten years, hepatocellular carcinoma after the stage of cirrhosis develops in a smaller proportion. Such evolution depends on genetic (gene polymorphysms) and environmental factors. The latter are the only ones that can be modified, thus the importance of treating (abdominal) obesity $[49,63]$. However in the case of NAFLD, because hepatic fat deposit is different, in individuals with equivalent adiposity, other genetic and inflammatory factors such as TNF-alpha, IL-6, endoplasmic reticulum stress ... deserve a prominent position in the clinical management of obese children and adolescents.

\section{Preventive and therapeutic aspects}

It is worth mentioning the importance of the maternal situation of overweight or obesity besides the general preventive actions [64]. It is widely documented that the maternal obesity has adverse outcomes both for herself and for the offspring the (extreme) preterm delivery [65], being the most important risk even reducing weight in pre-pregnancy or the gestation weight gain (GWG) decreases the premature births and also the premature rupture of membranes [66]. Optimal fetal growth depends on the fetal nutrition mediated via maternal- fetal glucose/ insulin/ insulin-like growth factor axis, the point is that fetal growth restriction and fetal overgrowth have been related to 
later obesity development [67]. Important epidemiologic studies have shown that maternal obesity is associated with higher BMI at 2 years of age [68] and abdominal obesity to the excessive gestational weight gain [69].

The therapeutic actions are presently a subject of controversy particularly as regards the pharmacological treatment. In general therapy of comorbidities has two main branches, one for the treatment of the metabolic syndrome i.e. obesity and the other for specific comorbidities. Multidisciplinary lifestyle intervention has been considered as the only effective way to approach the former, reducing the energy balance and body mass index diminution (rBMI \%) of $10 \%$ is probably the most efficient way, achieving a relative body mass even for improving liver histology. Details of this wide program (diet, exercise and family involvement) have been described elsewhere [64]. Bariatric surgery has proved its usefulness in adults and now it is being applied to children and adolescents with notable improvements of comorbidities, although an experienced setting is required. Concerning the use of metformin in T2D, the initial enthusiasm has waned and probably the concomitant use of insulin would be advisable [70]. The long-acting basal insulin analogs such as insulin detemir, insulin glargine or even insulin degludec [71] used in the adult reduce nocturnal hypoglycemic episodes and can be used in pediatric patients in not well controlled type 2 diabetic patients. It is important to consider how the use of low caloric sweeteners could play an important role in prevention of T2D in patients at risk besides the reduction of caloric intake [72]. As regards cardiovascular disease, the present aim is to control hypertension by means of ACE inhibitors or receptor blockers for angiotensin among others. Recently some controversy about cardiovascular complications prevention through lifestyle change has occurred: the Look AHEAD research [73] is an important study carried out on more than 5000 overweight adults with T2D in which intensive lifestyle intervention has been made. Surprisingly the cardiovascular events were not reduced. By no means should these results should not jeopardize the effective action that such change of habits has on the well proved diminution of the other negative outcomes of obesity. [74] For NAFLD even a minimal reduction of overweight led to an improvement of this. For given reasons diet with high glucose and high fructose should be avoided, hence force food with low glycemic index and low fat should be set up, docosahexaenoic acid or other n-3 polyunsaturated fatty acids have been not so successful as expected including the conjugated linoleic acid [75]. Conversely the pharmacological treatment of NAFLD is seldom used in pediatric patients [76]. The use of antioxidants including probucol (inhibitor of cholesterol oxidation and therefore foam cells production) has also been used in adults and children, but with irregular results. The use of insulin- sensitizing agents (glitazones, PPAR- $\gamma$ agonists) has a limited experience in pediatrics, finally metformin with or without added vitamin $\mathrm{E}$ was not superior to placebo [77]. A new way is opened with the use of pentoxyfilline, a xanthine derivative which lowers the TNFalpha activity $[78,79]$. Liver transplant is not a durable solution unless the treatment of obesity is controlled.
In conclusion, Obesity and insulin resistance are the most common ground factors for subtle development of comorbidities, the identification of metabolic syndrome in obese children will contribute to an early and specific diagnosis of them, thus prevention of NAFLD, CVD or T2D will only be possible in a vast majority of children and adolescents if obesity is controlled.

\section{Refrences}

1. De Filippo, G., Rendina, D., \& Strazzullo, P. (2010). Childhood obesity, other cardiovascular risk factors and premature death. $N$ Engl J Med, $362,1840-1842$.

2. Schuppan, D., Gorrell, M.D., Kein, T., Mark, M., \& Afdhal, N.H. (2010). The challenge of developing novel pharmacological therapies for nonalcoholic steatohepatitis. Liver Int, 30, 795-808.

3. Hongo, M., Hidaka, H., Sakaguchi, S., Nakanishi, K., Ichikawa, M., \& Hirota, N., et al. (2010). Association between serum uric acid levels and cardiometabolic risk factors among Japanese junior high school students. Circ J, 74, 1570-1575.

4. Fritsch, P., Kleber, M., Rusenkranz, A., Fritsch, M., Muntean, W., \& Mongge, H., et al. (2010). Haemostatic alterations in overweight children: Association between metabolic syndrome, thrombin generation and fibrinogen levels. Atherosclerosis, 212, 650-655.

5. Moya, M. (2010). A review of pediatric obesity in Europe from a clinical perspective. Eur Pediatrics, 4, 54-57.

6. Vague, J. (1956). The degree of masculine differentiation of obesities: a factor determining predisposition to diabetes, atherosclerosis, gout and uric calculous disease, Am J Clin Nutr, 4, 20-34.

7. Reaven, G. (2012). Insulin resistance and coronary heart disease in non-diabetic individuals. Arterioescler Thromb Vasc Biol, 32, 17541759.

8. Alberti, K.G., Zimmet, P., \& Shaw, J. (2006). Metabolic syndrome--a new world-wide definition. A Consensus Statement from the International Diabetes Federation. Diabet Med, 23, 469-480.

9. Alberti, K. G., Eckel, R. H., Grundy, S. M., Zimmet, P. Z., Cleeman, J. I., Donato, K. A, et al. (2009). Harmonizing the metabolic syndrome: a joint interim statement of the International Diabetes Federation Task Force on Epidemiology and Prevention; National Heart, Lung and Blood Institute; American Heart Association; World Heart Federation; International Atherosclerosis Society and International Association for the Study of Obesity. Circulation, 120, 1640-1645.

10.Zimmet, P., Alberti, K.G., Kaufman, F., Tajima, N., Silink, M., Arslanian, S., et al. (2007). The metabolic syndrome in children and adolescents - an IDF consensus report. Pediatr Diabetes, 8, 299-306.

11. Di Bonito, P., Forziato, C., Sanguigno, E., Di Fraia, T., Saitta, F., Lardino, M. R., et al. (2010). Prevalence of the metabolic syndrome using ATPderived definitions and its relation to insulin-resistance in a cohort of Italian outpatient children. J Endocrinol Invest, 33, 806-809.

12. Lobstein, T., \& Jackson-Leach, R. (2006). Estimated burden of pediatric obesity and co-morbidities in Europe. Part 2 numbers of children with indicators of obesity-related disease. Int J Pediatr Obes, 1, 33-41.

13. May, A.I., Kuklina, E.V., \& Yoon, P.W. (2012). Prevalence of cardiovascular disease risk factors among US adolescents 1999-2008. Pediatrics, 129, 1035-1041.

14. Shapiro, D.J., Hersh, A.L., Cabana, M.D., Sutherland, S.M., \& Patel, A.I. (2012). Hypertension screening during ambulatory pediatric visits in the United States, 2000-2009. Pediatrics, 130, 604-610. 
15. Yang, Q., Zhang, Z., Kuklina, E.V., Fang, J., Ayala, C., Hong, Y., et al. (2012). Sodium intake and blood pressure among US children and adolescents. Pediatrics, 130, 611-619.

16. Friedemann, C., Henegan, C., Mahtani, K., Thompson, M., Perera, R., \& Ward, A.M. (2012). Cardiovascular disease risk in healthy children and its association with body mass index: systematic review and meta-analysis. $B M J, 25$.

17. Ruiperez, C., Juste, M., \& Moya, M. (2008). Alteration of left ventricular myocardial characteristics associated to obesity in children. Invest Nutr Alim Pediatr.

18. Cook, S., Weitzman, M., Auinger, P., Nguyen, M., \& Dietz, W.H. (2003) Prevalence of a Metabolic Syndrome Phenotype in Adolescents. Findings from the third National Health and Nutrition Examination Survey, 1988-1994. Arch Pediatr Adolesc Med, 157, 821-827.

19. De Ferranti, S. D., \& Osganian, S. K. (2007). Epidemiology of pediatric metabolic syndrome and type 2 diabetes mellitus. Diab Vasc Dis Res, 4, 285-296.

20. Park, J., Hilmers, D. C., Mendoza, J. A., Stuff, J. E, Liu, Y., \& Nicklas, T.A (2010). Prevalence of Metabolic Syndrome and obesity in adolescents aged 12 to 19 years. Comparison between the United States and Korea. J Korean Med Sci, 25, 75-82.

21.Pergher, R. N., Melo, M. E., Halpern, A., \& Mancini M. C. (2010). Is a diagnosis of metabolic syndrome applicable to children? J Pediatr (Rio J), 86, 101-108.

22. O'Sullivan, T. A., Lyons-Wall, P., Bremmer, A. P., Ambrosini, G. L., Huang, R. C., Belin L. J., et al. (2010). Dietary glycaemic carbohydrate in relation to the metabolic syndrome in adolescents: comparison of different metabolic syndrome definitions. Diabet Med, 27, 770-778.

23. Bremer, A. A., Byrd, R. S., \& Auinger, P. (2012). Racial trends in sugarsweetened beverage consumption among US adolescents: 19982004. Int J Adolesc Med Health, 23, 26-30.

24. DeBoer, M. D., \& Gurka, M. J. (2010). Ability among adolescents for the metabolic syndrome to predict elevations in factors associated with type 2 diabetes and cardiovascular disease: data from the national health and nutrition examination survey 1992-2006. Metab Syndr Relat Disord, 8, 343-353.

25. Okosun, I. S., Seale, J. P., Boltri, J. M., \& Davis-Smith, M. (2012). Trends and clustering of cardiometabolic risk factors in American adolescents from 1999 to 2008. J Adolesc Health, 50, 132-139.

26.Zeelie, A., Moss S. J., \& Kruger, H. S. (2010). The relationship between body composition and selected metabolic syndrome markers in black adolescents in South Africa: the play study. Nutrition, 26, 1059-1064.

27. Kang, H. T., Lee, H. R., Shin, J. R., Park, B. J., \& Lee, Y. J. (2010). Association between screen time and metabolic syndrome in children and adolescents in Korea: the 2005 Korean National Health and Nutrition Examination Survey. Diabetes Res Clin Pract, 89, 72-78.

28. Okosun, I. S., Boltri, J. M., Lyn, R., \& Davis-Smith, M. (2010). Continuous metabolic syndrome risk score, body mass index percentile and leisure time physical activity in American children. J Clin Hypertens (Greenwich), 12, 636-644.

29. Pin, G., Cubel, M., Martin, G., Lluch, M., \& Morell, M. (2011). Habits and sleep problems in the Valencian community. Opinion of the child himself. An Pediatr [Barc], 74, 103-115.

30. Juárez-López, C., Klünder, M., Medina-Bravo, P., Madrigal-Azcárate, A., Mass-Díaz, E., \& Flores-Huerta, S. (2010). Insulin resistance and its association with the components of the metabolic syndrome among obese children and adolescents. BMC Public Health, 10, 318.

31. Bambrilla, P., Crino, A., Bedogni, G., Bosio, L., Cappa, M., Corrias, A., et al. (2011). Metabolic syndrome in children with Prader-Willi syndrome: The effect of obesity. Nutr Metab Cardiovasc Dis, 21, 269-276.

32. Povel, C. M., Boer, J. M., Reiling, E., \& Feskens, E. J. (2011). Genetics variants and the metabolic syndrome: a systematic review. Obes Rev, $12,952-967$.

33. Lusis, A. J., Attie, A. D., \& Reue, K. (2008). Metabolic syndrome: from epidemiology to systems biology. Nat Rev Genet, 9, 819-830.

34.Pal, A., Barber, T. M., Van de Bunt, M., Rudge, S. A., Zhang, Q., Lachlan, K. L., et al. (2012). PTEN mutations as a cause of constitutive insulin sensitivity and obesity. N Engl J Med, 367, 1002-1011.

35. Owen, J. L., Zhang, Y., Bae, S. H., Farooqi, M. S., Liang, G., Hammer, R. E., et al. (2012). Insulin stimulation of SERBP-1c processing in transgenic rat hepatocytes requires p70 S6-kinase. Proc Natl Acad Sci U S A, 109, 16184-16189.

36. Dimitriadis, G., Cryer, P., \& Gerich, J. (1985). Prolonged hyperglycemia during infusion of glucose and somatostatin impairs pancreatic A- and B-cell responses to decrements in plasma glucose in normal man: evidence for induction of altered sensitivity to glucose. Diabetologia, $28,63-69$.

37.Zavaroni, I., Bonora, E., Pagliara, M., Dall'Aglio, E., Luchetti, I., Buonanno, G., et al. (1989). Risk factors for coronary artery disease in healthy persons with hyperinsulinemia and normal glucose tolerance. N Eng J Med, 320, 702-706.

38. Boden, G., \& Hoeldtke, R. D. (2003). Nerves Fat and Insulin resistance. N Engl J Med, 349, 1966-1967.

39. Grundy, S. M., Cleeman, J. L., Daniels, S. R., Donato, K. A., Eckel, R. H., Franklin, B. A., et al. (2005). Diagnosis and management of the metabolic syndrome: an American Heart Association, National Heart, lung and Blood Institute Scientific Statement. Circulation, 112, 27352752.

40. Kim, S. H., \& Reaven, G. (2010). Obesity and insulin resistance: an ongoing saga. Diabetes, 59, 2105-2106.

41.Lee, S., Bacha, F., Gungor, N., \& Arslanian, S. A. (2006). Waist circumference is an independent predictor of insulin resistance in black and white youths. J Pediatr, 148, 188-194.

42. Lee, S., Bacha, F., \& Arslanian, S. A. (2006). Waist circumference, blood pressure and lipid components of the metabolic syndrome. J Pediatr, $149,809-816$

43. Orsi, C. M., Hale, D. E., \& Lynch, J. L. (2011). Pediatric obesity epidemiology. Curr Opin Endocrinol Diabetes Obes, 18, 14-22.

44. Devadason, C. A., \& Scheimann, A. O. (2012). Overview of screening methods for fatty liver disease in children. World J Hepatol, 4, 1-4.

45. Ge, Q., Huang, N., Wynn, R. M., Li, Y., Du, X., Miller, B., et al. (2012). Structural characterization of a unique interface between carbohydrate response element-binding protein [ChREBP] and 14-3$3 \beta$ protein. J Biol Chem, 287, 41914-41921.

46. Aerberli, I., Hochuli, M., Gerber, P. A., Sze, L., Murer, S. B., Tappy, L. et al. (2013). Moderate amounts of fructose consumption impair insulin sensitivity in healthy young men: A randomized controlled trial. Diabetes Care, 36, 150-156.

47. Tilq, H., \& Moschen, A. (2010). Update on nonalcoholic fatty liver disease: genes involved in nonalcoholic fatty liver disease and associated inflammation. Curr Opin Clin Nutr Metab Care, 13, 391-396. 
48. Kumashiro, N., Erion, D. M., Zhang, D., Khan, M., Beddow, S. A., Chu, X., et al. (2011). Cellular mechanism of insulin resistance in nonalcoholic fatty liver disease. Proc Natl Acad Sci USA, 108, 16381-16385.

49. Barshop, N. J., Francis, C. S., Schwimmer, J. B., \& Lavine, J. E. (2009). Nonalcoholic fatty liver disease as a comorbidity of childhood obesity. Ped Health, 3, 271-281.

50. Schwimmer, J. B., Deutsch, R., Kahen, T., Lavine, J. E., Stanley, C., \& Behling, C. (2006). Pevalence of fatty liver in children and adolescents. Pediatrics, 118, 1388-1393.

51. Szczepaniak, L. S., Nuremberg, P., Leonard, D., Browning, J. D., Reingold, J. S., Grundy, S., et al. (2004). Magnetic resonance spectroscopy to measure hepatic triglyceride content: prevalence of hepatic steatosis in the general population. Am J Physiol Endocrinol Metab, 288, E462428.

52. Schwimmer, J. B., Behlingm, C., Newbury, R., Deutsch, R., Nievergelt, C., Schork, N. J., et al. (2005). Histopathology of pediatric nonalcoholic fatty liver disease. Hepatology, 42, 641-649.

53. Brunt, E. M., \& Tiniakos, D. G. (2010) Histopathology of nonalcoholic fatty liver diseases. World J Gastroenterol, 16, 5286-5296.

54. Manco, M., Marcellini, M., De Vito, R., Comparcola, D., Sartorelli, M. R., Nobili, V., et al. (2008). Metabolic syndrome and liver histology in pediatric non-alcoholic steatohepatitis. Int J Obes [Lond], 32, 381-387.

55. Vajro, P., Lenta, S., Socha, P., Dhawan, A., McKiernan, P., Baumann, U., et al. (2012). Diagnosis of nonalcoholic fatty liver disease in children and adolescents: position paper of the ESPGHAN Hepathology Committee. J Pediatr Gastroenterol Nutr, 54, 700-713.

56. Nobili, V., Svegliati-Baroni, G., Alisi, A., Miele, L., Valennti, L., \& Vajro, P. (2012). A360-degree overview of pediatric NAFLD: recent insights. J Hepatol, 58, 1218-1229.

57. Patton, H. M., Lavine, J. E., Van Natta, M. L., Schwimmer, J. B., Kleiner, D, Molleston, J., et al. (2008). Clinical correlates of histopathology in pediatric nonalcoholic steatohepatitis. Gastroenterology, 135, 1961-1971.

58. Pacifico, L., Di Martino, M.D., Catalano, C., Panebianco, C., Bezzi, M., Anania, C., et al. (2011). T1-weighted dual-echo MRI for fat quantification in pediatric nonalcoholic fatty liver disease. World $J$ Gastroenterol, 17, 3012-3019.

59. Shannon, A., Alkhouri, N., Carter-Kent, C., Monti, L., Devito, R., Lopez, R., et al. (2011). Ultrasonographic quantitative estimation of hepatic steatosis in children with [NAFDL]. J Pediatr Gastroenterol Nutr, 53, 190-195.

60. Alkhouri, N., Sedki, E., Alisi, A., Lopez, R., Pinzani, M., Feldstein, A. E, et al. (2013). Combined pediatric NAFDL fibrosis index and transient elastography to predict clinically significant fibrosis in children with fatty liver disease. Liver Int, 33, 79-85.

61. Molleston, J. P., White, F., Teckman, J., \& Fitzgerald, J.F. (2002) Obese children with steatohepatitis can develop cirrhosis in childhood. Am J Gastroenterol, 97, 2460-2462.

62. Feldstein, A. E., Charatcharoenwitthaya, P., Treeprasertsuk, S., Benson, J. T., Enders F.B., \& Angulo, P. (2009). The natural history of nonalcoholic fatty liver disease in children a follow-up study for up to 20 years. Gut, $58,1538-1544$.
63. Day, C. P. (2012). Clinical spectrum and therapy of non-alcoholic steatohepatitis. Dig Dis, 1, 69-73.

64. Moya, M. (2008). An update in prevention and treatment of pediatric obesity. World J Pediatr, 4, 173-185.

65. Cnattingius, S., Villamor, E., Johansson, S., Edstedt Bonamy, A. K., Persson, M., Wikström, A. K., et al. (2013). Maternal obesity and risk of preterm delivery. JAMA, 309, 2362-2370.

66. Masho, S. W., Bishop, D. L., \& Munn, M. (2013). Pre-pregnancy BMI and weight gain: where is the tipping point for preterm birth? BMC Pregnancy and Childbirth, 13, 120.

67. Bloomfield, F. H., Spiroski, A. M., \& Harding, J. E. (2013). Fetal growth factors and fetal nutrition. Semin Fetal Neonatal Med.

68. Flores, G., \& Lin, H. (2013). Factors predicting overweight in US kindergartners. Am J Clin Nutr, 97, 1178-1187.

69. Ensenauer, R., Chmitorz, A., Riedel, C., Fenske, N., Hauner, H., NennstielRatzel, U., et al. (2013). Effects of suboptimal or excessive gestational weight gain on childhood overweight and abdominal adiposity: results from a retrospective cohort study. Int J Obes (Lond), 37, 505-512.

70. Copeland, K.C., Silverstein, J., Moore, K.R., Prazar, G.E., Raymer, T., Shiffman, R.N., et al. (2013). Management of newly diagnosed type 2 diabetes mellitus [T2DM] in children and adolescents. Pediatrics, 131, 364-382.

71. Moghissi, E. (2013). Management of Type 2 Diabetes Mellitus in Older Patients: Current and Emerging Treatment Options. Diabetes Ther.

72. Johnston, C. A., Stevens, B., \& Forey, J. P. (2013). The role of Lowcalorie Sweeteners in Diabetes. US Endocrinology, 9, 13-15.

73.Look AHEAD Research Group., Wing, R.R., Bolin, P., Brancati, F.L., Bray, G.A., Clark J. M., et al. (2013). Cardiovascular Effects of Intensive Lifestyle Intervention in Type 2 Diabetes. N Engl J Med, 369, 145-154.

74. Gerstein, H.C. (2013). Do Lifestyle Changes Reduce serious Outcomes in Diabetes? N Eng J Med, 369, 189-190.

75. Moya, M., Juste, M., \& Caturla, J. (2010). Changes in adiposity estimated by dual energy X-ray attenuation (DXA) in obese pediatric patients. In R. Sepiashvili, \& Medimond. Bologna (Eds.), In Advances in Allergy, Asthma \& Immunology: From Basic Science to Clinical Management. (pp. 179-183). Dubai.

76. Feldstein, A. (2013). NAFDL in children. In G. C. Farrell, A. J. McCullough, \& C. P. Day (Eds.), In Non-alcoholic fatty liver disease: a practical guide. (pp.171-181). Wiley-Blackwell.

77. Reinehr, T., Schmidt, C., Toschke, A.M., \& Andler, W. (2009). Lifestyle intervention in obese children with non-alcoholic fatty liver disease: 2-year follow-up study. Arch Dis Child 94, 437-442.

78. Deree, J., Martins, J.O., Melbostad, H., Loomis, W.H., \& Coimbra, R. (2008). Insights into the regulation of TNF-alpha production in human mononuclear cells: the effects of non-specific phosphodiesterase inhibition. Clinics (Sao Paulo), 63, 321-328.

79. Dor, Y., \& Glaser, B. (2013). Beta-cell differentiation and type 2 diabetes. N Engl J Med 368, 572-573. 